\title{
Four years experience of first-trimester nuchal translucency screening for fetal aneuploidies with increasing regional availability
}

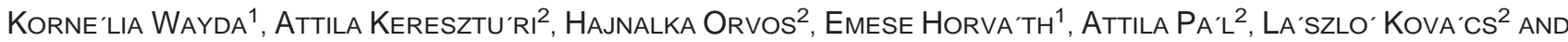 \\ JA'NOS SZABO'-1 \\ From the Departments of ${ }^{1}$ Medical Genetics and ${ }^{2}$ Obstetrics and Gynecology, Albert Szent-Györgyi Medical and \\ Pharmaceutical Center, University of Szeged, Szeged, Hungary
}

\begin{abstract}
Acta Obstet Gynecol Scand 2001; 80: 1104-1109. (C) Acta Obstet Gynecol Scand 2001
Background. A prospective screening study was carried out at the regional genetic and perinatal center in South Hungary in order to determine the efficiency of first-trimester nuchal translucency screening for fetal aneuploidies, following augmentation of the availability of nuchal translucency screening in the region by the inclusion of newly-trained hospital sonographers.

Methods. Nuchal translucency thickness was measured by transvaginal sonography in 7,044 women with singleton or multiple pregnancies at weeks 10-12. Fetal karyotyping was performed when the nuchal translucency was $\geq 2.5 \mathrm{~mm}$, and in women with fetuses at high cytogenetic risk.

Results. Follow-up was performed in 6,841 of the 7,044 screened women. An abnormal karyotype was found in 33 cases $(0.48 \%)$. The level of increased nuchal translucency was $4.5 \%$ at a cutoff of $\geq 2.5 \mathrm{~mm}$, and $2.8 \%$ at a cutoff of $\geq 3 \mathrm{~mm}$. Seventeen cases of trisomy 21 , eight of trisomy 18 , four of trisomy 13 , one of $45, \mathrm{X}$, one of triploidy and two cases with other chromosomal abnormalities were detected. In the 33 fetuses with a chromosomal abnormality, the nuchal translucency thickness was $<2.5 \mathrm{~mm}$ in a case of trisomy $18, \geq 2.5 \mathrm{~mm}$ in 32 cases and $\geq 3 \mathrm{~mm}$ in 28 cases. With cutoffs of $2.5 \mathrm{~mm}$ and $3 \mathrm{~mm}$, the sensitivity was $96.97 \%$ and $84.85 \%$, respectively.

Conclusions. Application of a nuchal translucency thickness cutoff of $2.5 \mathrm{~mm}$ is highly efficient for the screening of fetal aneuploidies at 10-12 weeks. This efficiency can be maintained by increasing the regional availability of nuchal translucency screening through the inclusion of newly-trained hospital sonographers.
\end{abstract}

Key words: fetal aneuploidies; first-trimester screening; nuchal translucency

Submitted 29 March, 2001

Accepted 13 August, 2001

The increased accumulation of nuchal fluid in the first-trimester fetus (1), called increased nuchal translucency (NT) in consequence of its ultrasonographic feature (2), has proved to be a very efficient marker for the screening of trisomy 21, other fetal aneuploidies (2-4), fetal cardiac defects

\section{Abbreviations:}

NT: nuchal translucency; CVS: chorionic villus sampling; AC: amniocentesis; CC: cordocentesis; AFP: alfa-fetoprotein.
$(5,6)$, certain genetic syndromes (5-7) and structural abnormalities $(5,6,8)$ in clinical studies $(5-$ 16). For this reason, the method is currently at the focus of international interest, in particular because the fetal NT screening yields different rates of efficiency in different hands.

Our prenatal center was among the first to introduce first-trimester ultrasound screening, and has maintained a high rate of efficiency from the start $(1,3,15)$. The present paper reports on four years 
of experience with the method, following the change-over from single-center screening with two operators to four-center screening involving the inclusion of six newly-trained operators; a NT thickness cutoff of $2.5 \mathrm{~mm}$ was used. The computerestimated risk (developed and provided by the Fetal Medicine Foundation and Harris Birthright Research Center for Fetal Medicine, London, UK) was introduced from October, 1997 to facilitate genetic counseling and decisions relating to invasive tests.

\section{Material and methods}

In a prospective screening study between 1995 and 1998 at the Szeged Univeristy Prenatal Clinic and at four regional hospitals, the NT thickness was measured at $10-12$ weeks of gestation by transvaginal ultrasound examination in 7,044 women with singleton or multiple pregnancies. Informed consent was obtained before ultrasound examinations and invasive testing, and all the women participated in the study voluntarily.

The study did not cover the whole population of the region, in spite of the increasing quantity of available information on the importance of firsttrimester ultrasound screening.

The ultrasound examinations were performed by using a $6.5-7.5 \mathrm{MHz}$ vaginal probe (Combison 530, 3D, Kretz Technik). The NT thickness was measured at 10-12 weeks of gestation between the outer skin surface and the soft tissue overlying the fetal spine in the sagittal plane of the fetus in a 'quiet or neutral' position. The maximal zoom of the ultrasound screen was used. The fetal NT thickness was evaluated only after embryo movements, in order to distinguish between the fetal skin contour and the amnion. The number of fetuses, the crown-rump length, the fetal movement and heart activity, the extremities and fetal structural anomalies were also evaluated. Nuchal translucency thicknesses of $\geq 2.5 \mathrm{~mm}$ were defined as positive cases and were referred from the regional hospitals to our tertiary genetic counseling clinic for consideration of an invasive test.

All the sonographers involved had received a license for first-trimester scanning after theoretical and practical training at our center. Theoretical courses were held twice a year, while practical training was continuous.

Invasive tests were offered according to the classical genetic indications, i.e. a maternal age $\geq 35$ years, a previous child with chromosomal abnormalities, parental chromosomal abnormalities, and a NT $\geq 2.5 \mathrm{~mm}$. The policy of offering invasive tests was as follows: an earlier rapid test (chorionic villus sampling (CVS)) was advised when the NT was $\geq 3 \mathrm{~mm}$, irrespective of the maternal age. Women with a NT between 2.5 and $2.9 \mathrm{~mm}$ could choose from among CVS, amniocentesis (AC) or cordocentesis (CC). Invasive tests were offered to patients over 35 years of age, irrespective of the NT, in accordance with the current legal regulations in Hungary. The invasive procedures were performed transabdominally with ultrasonically guided needles, using a free hand technique. The outer diameters of the CVS, AC and CC needles were $1.1 \mathrm{~mm}, 0.8 \mathrm{~mm}$ and $0.8 \mathrm{~mm}$, respectively.

For those who declined invasive tests, a thorough ultrasound follow-up was advised in order to seek early second-trimester markers of fetal aneuploidies such as an increased NT, cardiac defects, echogenic bowels, pyelectasis, and other structural defects, combined with the alfa-fetoprotein (AFP) level at 16 weeks of gestation. All other women underwent an anomaly scan at weeks $18-20$.

Information on the pregnancy follow-up and outcome was obtained through written questionnaires or by telephone from the patients, from the regional hospitals and/or from the nursing midwife network.

From October 1997, we used in parallel the USS program kindly provided by Professor Nicolaides from the Fetal Medicine Foundation, London, but the NT thickness of $2.5 \mathrm{~mm}$ remained as an interventional cutoff.

\section{Results}

Between January 1995 and December 1998, 7,044 women were enrolled in the first-trimester ultrasound screening study. Of these, 203 pregnancies were excluded from further analysis since it was impossible to obtain any written or oral information concerning the pregnancy outcome.

As regards the remaining 6,841 pregnancies, 4,821 were examined in the regional centers and $2,020(29.5 \%)$ were referred to or primarily examined at the Department of Obstetrics and Gynecology. There were $6,750(98.67 \%)$ singleton and 91 $(1.33 \%)$ multiple pregnancies (85 sets of twins, three sets of triplets, two sets of quadruplets and one set of quintuplets). The two sets of quadruplets and the quintuplet pregnancy were each reduced to two fetuses at the request of the parents. All these multiplets were euploid. Spontaneous abortion occurred between the NT screening and the planned invasive tests in eight patients, and up to week 20 in another 15 pregnancies.

The median maternal age was 31 years (range 16-46). The NT was $\geq 3 \mathrm{~mm}$ in $191(2.8 \%)$ and $\geq 2.5 \mathrm{~mm}$ in $308(4.5 \%)$ cases (Table I), to whom invasive tests were offered; however, 54 declined.

Six hundred and seven $(8.87 \%)$ of the screened 
Table I. Distribution of nuchal translucency among pregnant women screened during the first trimester

\begin{tabular}{lccc}
\hline $\begin{array}{l}\text { Nuchal } \\
\text { translucency }(\mathrm{mm})\end{array}$ & $<35$ years & $\geq 35$ years & $\begin{array}{c}\text { Total number } \\
\text { of cases }\end{array}$ \\
\hline $0-0.9$ & 773 & 288 & 1,061 \\
$1-1.9$ & 2,673 & 1,638 & 4,311 \\
$2-2.4$ & 686 & 475 & 1,161 \\
Total $<2.5 \mathrm{~mm}$ & $4,132(97.43 \%)$ & $2,401(92.35 \%)$ & $6,533(95.5 \%)$ \\
$2.5-2.9$ & 54 & 63 & 117 \\
$3-3.9$ & 24 & 91 & 115 \\
$4-4.9$ & 11 & 24 & 35 \\
$5-5.9$ & 9 & 11 & 20 \\
$6-6.9$ & 5 & 7 & 12 \\
$7-7.9$ & 2 & 2 & 4 \\
$8-8.9$ & 2 & 1 & 3 \\
$9+$ & 2 & 0 & 2 \\
Total $\geq 2.5 \mathrm{~mm}$ & $109(2.57 \%)$ & $199(7.65 \%)$ & $308(4.5 \%)$ \\
Total: & 4,241 & 2,600 & 6,841 \\
\hline
\end{tabular}

women underwent invasive genetic tests: 463 involved CVS, $97 \mathrm{AC}$ and $47 \mathrm{CC}$. Two hundred and fifty-four of the 607 invasive tests were based on a
NT thickness of $\geq 2.5 \mathrm{~mm}, 323$ were based on maternal age ( $\geq 35$ years) alone $(\mathrm{NT}<2.5 \mathrm{~mm})$ and 30 were based on other indications (e.g. previous parental or neonatal chromosomal abnormalities). All those women who did not undergo invasive tests gave birth to apparently normal neonates, as checked by pediatricians.

An abnormal karyotype was found in 33 $(0.48 \%)$ cases, i.e. $5.4 \%$ of the total number of those who participated in invasive examinations (Table II). A NT $\geq 2.5 \mathrm{~mm}$ was measured in 32 $(96.97 \%)$ of the fetuses with an abnormal karyotype. For a cutoff of $3 \mathrm{~mm}$, this changed to $84.8 \%$. In the group of invasive tests based on maternal age and previous chromosomal abnormalities (353 cases), only one chromosomal aneuploidy was found (Table II, serial number 18).

The mean NT values were $3.76 \mathrm{~mm}$ for trisomy $21,5.75 \mathrm{~mm}$ for trisomy 18 and $4.23 \mathrm{~mm}$ for trisomy 13 . The maternal age was $\geq 35$ years in 18 $(54.54 \%)$ of the 33 aneuploid pregnancies. A fetal NT thickness $<3 \mathrm{~mm}(2.8 \mathrm{~mm})$ was measured in only one of the 15 mothers $<35$ years of age (33

Table II. Chromosomal aneuploidies screened by nuchal translucency measurement at a gestational age of 70-91 days

\begin{tabular}{|c|c|c|c|c|}
\hline Serial number & $\begin{array}{l}\text { Maternal age } \\
\text { (years) }\end{array}$ & $\begin{array}{l}\text { Gestational age } \\
\text { (days) }\end{array}$ & $\begin{array}{l}\text { Nuchal translucency } \\
\qquad(\mathrm{mm})\end{array}$ & Karyotype \\
\hline 1 & 42 & 86 & 2.5 & $47, X X+21$ \\
\hline 2 & 33 & 71 & 2.8 & $47, X Y+21$ \\
\hline 3 & 36 & 91 & 2.8 & $47, X Y+21$ \\
\hline 4 & 42 & 70 & 2.9 & $47, X Y+21$ \\
\hline 5 & 25 & 85 & 3 & $47, X X+21$ \\
\hline 6 & 38 & 89 & 3.1 & $47, X Y+21$ \\
\hline 7 & 36 & 88 & 3.1 & $47, X Y+21$ \\
\hline 8 & 39 & 74 & 3.2 & $47, X X+21$ \\
\hline 9 & 40 & 73 & 3.3 & $47, X Y+21$ \\
\hline 10 & 30 & 90 & 3.4 & $47, X Y+21$ \\
\hline 11 & 27 & 73 & 3.5 & $47, X Y+21$ \\
\hline 12 & 28 & 86 & 3.7 & $47, X X+21$ \\
\hline 13 & 23 & 91 & 4 & $47, X Y+21$ \\
\hline 14 & 38 & 91 & 4 & $47, X Y+21$ \\
\hline 15 & 36 & 91 & 4.1 & $47, X X+21$ \\
\hline 16 & 39 & 80 & 6.3 & $47, X X+21$ \\
\hline 17 & 36 & 70 & 8.2 & $47, X Y+21$ \\
\hline 18 & 41 & 80 & 1.2 & $47, X Y+18$ \\
\hline 19 & 33 & 78 & 4.2 & $47, X Y+18$ \\
\hline 20 & 36 & 78 & 4.3 & $47, X X+18$ \\
\hline 21 & 33 & 80 & 4.6 & $47, X Y+18$ \\
\hline 22 & 26 & 91 & 5.2 & $47, X X+18$ \\
\hline 23 & 29 & 87 & 7.4 & $47, X Y+18$ \\
\hline 24 & 40 & 82 & 8 & $47, X X+18$ \\
\hline 25 & 24 & 89 & 11.1 & $47, X Y+18$ \\
\hline 26 & 20 & 83 & 3.1 & $47, X Y+13$ \\
\hline 27 & 40 & 73 & 3.6 & $47, X X+13$ \\
\hline 28 & 42 & 75 & 3.9 & $47, X Y+13$ \\
\hline 29 & 28 & 80 & 6.3 & $47, X Y+13$ \\
\hline 30 & 28 & 88 & 11 & $45, X 0$ \\
\hline 31 & 39 & 91 & 3 & 46XX/46XY/ 47XXX/47XXY \\
\hline 32 & 24 & 89 & 8.5 & $69, X X X$ \\
\hline 33 & 35 & 90 & 3.5 & $47, \mathrm{XY}+14 \mathrm{q}$ partial trisomy \\
\hline
\end{tabular}


Table III. Efficiency of nuchal translucency screening with a cutoff level of $\geq 2.5 \mathrm{~mm}$ for all aneuploidies and trisomy 21

\begin{tabular}{lcc}
\hline & All aneuploidies (\%) & Trisomy 21 (\%) \\
\hline Sensitivity & 96.97 & 100 \\
Specificity & 95.94 & 95.74 \\
Positive predictive value & 10.39 & 5.52 \\
Negative predictive value & 99.98 & 100 \\
False-positive rate & 4.05 & 4.26 \\
\hline
\end{tabular}

Table IV. Efficiency of nuchal translucency screening with a cutoff level of $\geq 3$ $\mathrm{mm}$ for all aneuploidies and trisomy 21

\begin{tabular}{lcc}
\hline & All aneuploidies (\%) & Trisomy 21 (\%) \\
\hline Sensitivity & 84.85 & 76.47 \\
Specificity & 97.61 & 97.39 \\
Positive predictive value & 14.66 & 6.81 \\
Negative predictive value & 99.92 & 99.94 \\
False-positive rate & 2.39 & 2.61 \\
\hline
\end{tabular}

years old), while four of the fetuses of the 18 women aged $\geq 35$ years had a NT thickness $<3$ $\mathrm{mm}(1.2,2.5,2.8$ and $2.9 \mathrm{~mm})$.

In the $191(2.8 \%)$ fetuses where the NT was $\geq 3$ $\mathrm{mm}$, the prevalence of chromosomal defects was $14.7 \%$ (28 cases). When a cutoff of $2.5 \mathrm{~mm}$ was applied (308 pregnant women), this figure changed to $10.4 \%$ (32 cases).

Tables III and IV present the sensitivity, the specificity, the positive and negative predictive values and the false-positive rate for cutoff values of $2.5 \mathrm{~mm}$ and $3 \mathrm{~mm}$ in all aneuploid cases and in cases with trisomy 21 .

\section{Discussion}

Efforts are currently being made worldwide to achieve the recognition of fetal chromosomal aneuploidies at the earliest possible gestational age. Though a number of second-trimester ultrasonic markers of fetal aneuploidies have been described, such as a thickened nuchal pad, heart defects, a shorter humerus and femur, echogenic bowels, pyelectasis, etc. (17-19), none of them is specific and of value for efficient screening. Moreover, the search for these sonographic markers is time-consuming, and demands exceptional training, qualifications, experience and competence in ultrasound examinations.

The report by Szabó and Gellén (1990) (1) that the accumulation of nuchal fluid $\geq 3 \mathrm{~mm}$ thick as measured by high-resolution ultrasonography in the first-trimester embryo is associated with trisomy 21 is gaining increasing acceptance worldwide $(2,3,5,24,29)$. First-trimester NT screening for chromosomal aneuploidies is ever more widely utilized, but the efficiency is extremely variable: between 30 and 90\% (2, 7, 10, 14, 20-28). In Szeged, from the start we have placed special emphasis on the analysis of factors influencing the efficiency, and in the learning years we have maintained a high rate of efficiency $(88 \%)(15)$.

The Department of Medical Genetics is the only center in South Hungary where all prenatal counseling and cytogenetic studies are performed and to which all neonates with any indications of abnormality are referred. The ultrasound clinic is a third-level screening center.

\section{Cutoff levels}

The cutoff levels of first-trimester NT thickness used by different authors range from 2 to $5 \mathrm{~mm}$ $(2,7,10,20-26)$. In practice, we use a $2.5 \mathrm{~mm}$ cutoff. Since the frequency of a NT thickness $>3 \mathrm{~mm}$ in the general population is $2-3 \%$, invasive testing of these selected pregnancies means an appreciable load for genetic centers. If we use a lower cutoff, we can detect more fetal aneuploidies, but the workload increases significantly. A practically acceptable cutoff value is therefore necessary to distinguish affected cases from normal ones. It is known that the NT thickness normally increases with the crown-rump length (9), and the use of a single cutoff may bias the sensitivity. If the NT screening concentrates on weeks 11-12, a cutoff of $2.5 \mathrm{~mm}$, which yields more than $90 \%$ sensitivity, is acceptable in practice.

With a cutoff of $3 \mathrm{~mm}$ or higher $(9,13,22)$, the reported sensitivity for all aneuploidies ranges between $46 \%$ and $69 \%$, and that for trisomy 21 between $54 \%$ and $77 \%$. The sensitivity we obtained by using a $2.5 \mathrm{~mm}$ cutoff $(96.97 \%$ for all aneuploidies and $100 \%$ for trisomy 21 ) is highly comparable with the literature data.

Recent studies have used cutoff levels calculated via percentile curves or the risk calculation program of the Fetal Medicine Foundation, UK. This program calculates the risk of aneuploidies from a combination of the maternal age and the gestational age-related prevalence, multiplied by a likelihood ratio depending on the deviation from the normal in NT thickness for the crown-rump length. Use of a risk calculation involving a combination of the maternal age, gestational age, NT thickness and former aneuploidy allowed the setting-up of a risk cutoff level $\geq 1: 300$ (24). The method of risk calculation reported by Snijders et al. (1998) (24) is a more comprehensive approach, which collects the known factors responsible for the actual risk of aneuploidy. Their risk calculation program led to a detection rate of $82 \%$ for Down 
syndrome and of $78 \%$ for other chromosomal aneuploidies.

In our opinion, it is useful to set up a standard of first-trimester ultrasound screening with a welldefined cutoff level, as there are centers in the developing areas which do not have the facilities to establish a computer calculation network. In addition, our study was conducted before the Fetal Medicine Foundation risk calculation was available. A well-defined cutoff level is of practical value for sonographers trained in NT measurement who screen in underdeveloped regions far from the centers and who need a practical solution. Our results suggest that $2.5 \mathrm{~mm}$ at $10-12$ weeks of gestation is a reasonable cutoff level for those who do not have the program as this yields an acceptable rate of first-trimester detection of fetal aneuploidies.

\section{Efficiency of NT screening with a cutoff of $2.5 \mathrm{~mm}$}

Both in our regional perinatal center and in Hungary overall, the proportion of pregnants aged over 35 years has been around 7\% during the last decade. The regulations require that they should be offered invasive tests, which result in only a 12 $15 \%$ detection rate of trisomy 21 at $50 \%$ uptake. With a NT thickness of $\geq 2.5 \mathrm{~mm}$, in the present study $4.5 \%$ of all pregnancies screened positive and they included $100 \%$ of the trisomy 21 cases and $96 \%$ of all aneuploidies. The sensitivity obtained in literature studies lay in the range $50-92 \%$ for all aneuploidies and $43-88 \%$ for trisomy $21(2,13,15$, 21, 22, 24).

In experienced hands, ultrasonographic evaluation of the fetus at 10-12 gestational weeks is one of the most efficient methods of screening chromosomal abnormalities. In the group of 353 women with a NT thickness of $<2.5 \mathrm{~mm}$ who underwent invasive tests, only one aneuploidy (trisomy 18) was found; this suggests that the measurement of NT thickness alone is a good selection criterion for invasive tests. The method has no adverse effects as concerns either the fetus or the pregnancy. A NT cutoff of $\geq 2.5 \mathrm{~mm}$ is a sensitive and effective criterion of selection of women for invasive tests.

The recognition of fetal aneuploidies at this gestational age and the early termination of the affected pregnancy may be less traumatic for couples who choose this option and they may have a healthy offspring sooner. A potential disadvantage of this early diagnosis is the identification of chromosomally abnormal pregnancies that are destined to miscarry. About $40 \%$ of trisomy 21 fetuses die between 12 weeks of gestation and term (30). Other benefits of the first-trimester scan include the confirmation that the fetus is alive, accu- rate dating of the pregnancy, the early diagnosis of multiple pregnancies and the detection of major structural abnormalities and missed abortion (6$8,16,31)$. General evaluation of the fetal structure simultaneously with NT measurement can reveal other structural abnormalities and allow efficient genetic counseling to be extended to more and more women, irrespective of their age.

\section{Acknowledgments}

The authors thank Ferenc Rácz, M.D., Béla Vásárhelyi, M.D., János Sikovanyecz, M.D., István Boleman, M.D., Dénes Kovács, M.D. and István Kajtár, M.D. for performing and evaluating the ultrasound examinations.

\section{References}

1. Szabó J, Gellén J. Nuchal fluid accumulation in trisomy-21 detected by vaginosonography. Lancet 1990; 2: 1133.

2. Nicolaides KH, Azar G, Byrne D, Mansur C, Marks K. Fetal nuchal translucency: ultrasound screening for chromosomal defects in first trimester of pregnancy. BMJ 1992; 304: 867-9.

3. Szabó J, Gellén J, Szemere G. First trimester aneuploid fetuses. Screening by vaginosonography. Prenat Diagn 1992; 12: S153.

4. Szabó J, Gellén J, Szemere G. Nonimmune hydrops in trisomy 18. Diagnosis by vaginosonography and chorionic villus sampling in the first trimester. Br J Obstet Gynaecol 1990; 97: 955-6.

5. Nicolaides KH, Sebire NJ, Snijders RJM. The 11-14-week scan. The diagnosis of fetal abnormalities. In: Nicolaides KH (Eds.): Diploma in Fetal Medicine Series. New York, London: Parthenon Publishing, 1999.

6. Souka AP, Snijders RJ, Novakov A, Soares W, Nicolaides $\mathrm{KH}$. Defects and syndromes in chromosomally normal fetuses with increased nuchal translucency thickness at 10 14 weeks of gestation. Ultrasound Obstet Gynecol 1998; 11: $391-400$.

7. Fisk NM, Vaughan J, Smidt M, Wigglesworth J. Transvaginal ultrasound recognition of nuchal edema in the firsttrimester diagnosis of achondrogenesis. J Clin Ultrasound 1991; 19: 586-90.

8. Souka AP, Nicolaides KH. Diagnosis of fetal abnormalities at the 10-14-week scan. Ultrasound Obstet Gynecol 1997; 10: $429-42$.

9. Savoldelli G, Binkert F, Achermann J, Schmid W. Ultrasound screening for chromosomal anomalies in the first trimester of pregnancy. Prenat Diagn 1993; 13: 513-18.

10. Johnson MP, Johnson A, Holzgreve W, Isada NB, Wapner RJ, Treadwell MC et al. First-trimester simple hygroma: Cause and outcome. Am J Obstet Gynecol 1993; 168: 15661.

11. Nadel A, Bromley B, Benaceraff B. Nuchal thickening or cystic hygromas in first and early second trimester fetuses: prognosis and outcome. Obstet Gynecol 1993; 82: 43-8.

12. Nicolaides KH, Brizot ML, Snijders RJM. Fetal nuchal translucency: ultrasound screening for fetal trisomy in the first trimester pregnancy. Br J Obstet Gynaecol 1994; 101: 782-6.

13. Comas C, Martinez JM, Ojuel J, Casals E, Puerto B, Borrell $\mathrm{A}$ et al. First-trimester nuchal edema as a marker of aneuploidy. Ultrasound Obstet Gynecol 1995; 5: 26-9.

14. Pandya PP, Santiago C, Snijders RJM, Nicolaides KH. First trimester fetal nuchal translucency. Curr Opin Obstet Gynecol 1995; 7: 95-102. 
15. Szabó J, Gellén J, Szemere G. First trimester ultrasound screening for fetal aneuploidies in women over 35 and under 35 years of age. Ultrasound Obstet Gynecol 1995; 5: $161-3$.

16. Rottem S. Early detection of structural anomalies and markers of chromosomal aberrations by transvaginal ultrasonography. Curr Opin Obstet Gynecol 1995; 7: 122-5.

17. Donnenfeld A, Mennuti M. Sonographic findings in fetuses with common chromosomal abnormalities. Clin Obstet Gynecol 1988; 31: 80-96.

18. Benacerraf B, Miller B, Frigoletto F. Sonographic detection of fetuses with trisomy 13 and 18: accuracy and limitations. Am J Obstet Gynecol 1988; 158: 404-9.

19. Nyberg D, Resta R, Luthy D, Hockok D, Mahony B, Hirsch J. Prenatal sonographic findings of Down syndrome: review of 94 cases. Obstet Gynecol 1990; 76: 370 7.

20. Scott F, Boogert A, Sinosich M, Anderson J. Establishment and application of a normal range for nuchal translucency across the first trimester. Prenat Diagn 1996; 16: 629-34.

21. Hafner E, Schuchter K, Liebhart E, Philipp K. Results of routine fetal nuchal translucency measurement at weeks $10-13$ in 4,233 unselected pregnant women. Prenat Diagn 1998; 18: 29-34.

22. Taipale P, Hiilesmaa V, Salonen R, Ylöstalo P. Increased nuchal translucency as a marker for fetal chromosomal defects. N Engl J Med 1997; 337: 1654-8.

23. Economides DL, Whitlow BJ, Kadir R, Lazanakis M, Verdin SM. First trimester sonographic detection of chromosomal abnormalities in an unselected population. $\mathrm{Br} \mathrm{J}$ Obstet Gynaecol 1998; 105: 58-62.

24. Snijders RJ, Noble P, Sebire N, Souka A, Nicolaides KH UK multicentre project on assessment of risk of trisomy 21 by maternal age and fetal nuchal-translucency thickness at 10-14 weeks of gestation. Fetal Medicine Foundation First Trimester Screening Group. Lancet 1998; 1; 352: 343-6.

25. Fukada Y, Yasumizu T, Takizawa M, Amemiya A, Hoshi $\mathrm{K}$. The prognosis of fetuses with a shortened femur and humerus length before 20 weeks of gestation. Int J Gynaecol Obstet 1997; 59: 119-22.

26. Zoppi MA, Ibba RM, Putzolu M, Floris M, Monni G. Assessment of risk for chromosomal abnormalities at 10 14 weeks of gestation by nuchal translucency and maternal age in 5,210 fetuses at a single center. Fetal Diagn Ther $2000 ; 15: 170-3$.

27. Brambati B, Cislaghi C, Tului L, Alberti E, Amidani M, Colombo U et al. First-trimester Down's syndrome screening using nuchal translucency: a prospective study in patients undergoing chorionic villus sampling. Ultrasound Obstet Gynecol 1995; 5: 9-14.

28. D’Ottavio G, Mandruzzato G, Meir YJ, Rustico MA, Fischer-Tamaro L, Conoscenti $\mathrm{G}$ et al. Comparisons of first and second trimester screening for fetal anomalies. Ann N Y Acad Sci 1998; 847: 200-9.

29. Stewart TL, Malone FD. First trimester screening for aneuploidy: nuchal translucency sonography. Semin Perinatol 1999; 23: 369-81.

30. Snijders RJ, Sebire NJ, Nicolaides KH. Maternal age and gestational age-specific risk for chromosomal defects. Fetal Diagn Ther 1995; 10: 356-67.

31. Devine PC, Malone FD. First trimester screening for structural fetal abnormalities: nuchal translucency sonography. Semin Perinatol 1999; 23: 382-92.

Address for correspondence:

Professor J. Szabó, M.D., Ph.D., D.Sc.

Department of Medical Genetics

Albert Szent-Györgyi Medical and Pharmaceutical Center

University of Szeged

H-6720, Szeged

Somogyi u. 4 .

Hungary

e-mail: szabo@comser.szote.u-szeged.hu 